\title{
Expressão e caracterização da glicoproteína D do herpesvírus equídeo 1 em Pichia pastoris
}

[Expression and characterization of equid herpesvirus 1 glycoprotein D in Pichia pastoris]

\author{
P.R.C. Rodrigues ${ }^{1}$, R.C. Cunha ${ }^{2}$, F.D.S. Santos ${ }^{2}$, V.S. Gonçalves ${ }^{2}$, P.M.M. Albuquerque ${ }^{2}$, \\ A.G. Santos Júnior ${ }^{2}$, M. Lima ${ }^{1}$, F.P.L. Leite ${ }^{2}$ \\ ${ }^{1}$ Faculdade de Veterinária - Universidade Federal de Pelotas - Pelotas, RS \\ ${ }^{2}$ Centro de Desenvolvimento Tecnológico - Universidade Federal de Pelotas - Pelotas, RS
}

\begin{abstract}
RESUMO
O herpesvírus equídeo 1 (EHV-1) apresenta distribuição mundial e causa graves prejuízos à equideocultura. É agente de surtos de doença respiratória, reprodutiva e neurológica, em equídeos jovens e adultos. A glicoproteína $\mathrm{D}(\mathrm{gD})$ do envelope viral é essencial para ligação e penetração em células permissivas e direcionamento do sistema imunológico do hospedeiro, induz respostas imunes humorais e celulares, sendo um antígeno apropriado para ser utilizado em vacinas e imunodiagnóstico. O objetivo deste trabalho foi expressar e caracterizar a gD do EHV-1 em Pichia pastoris para posterior utilização como antígeno em técnicas de imunodiagnóstico e formulação de vacinas recombinantes. Uma sequência de DNA que codifica uma forma truncada da gDEHV-1 foi clonada no vetor pPICZ $\alpha \mathrm{A}$ de expressão em $P$. pastoris. Obteve-se uma proteína de $\sim 41 \mathrm{kDa}$, como esperado. A proteína apresentou glicosilação entre $4 \mathrm{kDa}$ e $16 \mathrm{kDa}$, demonstrada por deglicosilação enzimática. A proteína recombinante foi caracterizada antigenicamente e imunogenicamente por Western blot, utilizando-se anticorpos policlonais equinos antiEHV-1, e por ELISA indireto em modelo murino, demonstrando que a gD recombinante manteve epítopos similares aos da proteína nativa. Esses resultados sugerem que a gDEHV-1 é um antígeno promissor para uso como imunobiológico no controle do EHV-1.
\end{abstract}

Palavras-chave: doenças víricas, proteínas recombinantes, equinos

\begin{abstract}
Equine herpesvirus 1 (EHV-1) has a worldwide distribution and causes serious damage to horse breeding. It is an agent of respiratory, reproductive and neurological disease outbreaks in young and adult equids. Viral envelope glycoprotein $D(g D)$ is essential for binding and penetration into permissive cells and targeting the host immune system, inducing humoral and cellular immune responses, and is an appropriate antigen for use in vaccines and immunodiagnostics. The objective of this work was to express in Pichia pastoris and to characterize EHV-1 gD for later use as an antigen in immunodiagnostic techniques and formulation of recombinant vaccines. A DNA sequence encoding a truncated form of gDEHV-1 has been cloned into the P. pastoris expression vector pPICZaA. A protein of $\sim 41 \mathrm{kDa}$ was obtained as expected. The protein presented glycosylation between $4 \mathrm{kDa}$ and $16 \mathrm{kDa}$, demonstrated by enzymatic deglycosylation. The recombinant protein was antigenically and immunogenically characterized by Western blot using equine polyclonal anti-EHV-1 antibodies, and by indirect ELISA in a murine model, demonstrating that the recombinant $g D$ maintained epitopes similar to those of the native protein. These results suggest that $g D E H V-1$ is a promising antigen for use as an immunobiological in the control of EHV-1.
\end{abstract}

Keywords: viral diseases, recombinant proteins, equines

Recebido em 18 de fevereiro de 2019

Aceito em 30 de agosto de 2019

E-mail: priccenteno@hotmail.com 


\section{INTRODUÇÃO}

O herpesvírus equídeo 1 (EHV-1) distribui-se mundialmente e é considerado o principal agente de abortamentos em equídeos, além de causar surtos de doença respiratória e ocasionalmente enfermidade neurológia (Patel e Heldens, 2005). Dos nove herpervírus equídeos atualmente identificados (Maxwell, 2017), somente o EHV1 (agente do aborto herpético equino) e o EHV-4 (agente da rinopneumonite viral equina) demonstraram importância clínica, epidemiológica e econômica (Harless e Pusterla, 2006).

A glicoproteína D do EHV-1 (gDEHV-1) é fundamental para a fusão do envelope viral com a membrana plasmática da célula hospedeira (Whittaker et al., 1992) e a dispersão célulacélula, sendo essencial para a infectividade do vírus (Sáenz e Urcuqui-Inchima, 2006). É uma proteína de $55 \mathrm{kDa}$, composta por dois polipeptídeos (Flowers e O'Callaghan, 1992). Devido a sua relevância no processo de replicação do EHV-1 e à capacidade de induzir resposta imune celular e humoral em modelos murino (Stokes et al., 1997) e equino (Foote et al., 2005; Weerasinghe et al., 2006), a gDEHV-1 tem sido utilizada para diagnóstico (Fuentealba et al., 2014) e produção de vacinas recombinantes experimentais (Zhang et al., 1998). Foi produzida em diversos sistemas de expressão de proteínas heterólogas: Escherichia coli (Love et al., 1992), baculovírus (Love et al., 1993) e Pichia pastoris (Ruitenberg et al., 2001).
A levedura metilotrófica $P$. pastoris é bastante utilizada para expressão de proteínas heterólogas, em detrimento de outros sistemas de expressão, por ser de fácil manipulação genética, expressar proteínas heterólogas em níveis elevados, promover O- e N-glicosilação e processar sequências sinais com rapidez, facilidade e economia (Cregg et al., 2000; Ahmad et al., 2014). O objetivo deste trabalho foi expressar e caracterizar a gDEHV-1 em $P$. pastoris para posterior utilização como antígeno em técnicas de imunodiagnóstico e produção de vacinas recombinantes.

\section{MATERIAL E MÉTODOS}

O plasmídeo sintético pPICZ $\alpha \mathrm{A}-\mathrm{gDEHV}-1$, contendo um fragmento de DNA de 1022 pb que corresponde a uma fração da gDEHV-1 (número de acesso do GenBank: AB279610.1), foi obtido junto à GenOne Soluções em Biotecnologia (RJ, Brasil). O plasmídeo pPICZ $\alpha$ A (Invitrogen, SP, Brasil) contém: o promotor $A O X 1$ para expressão do gene de interesse, a região terminadora de transcrição do gene $A O X 1$, o sinal de secreção $\alpha$ factor do Saccharomyces cerevisiae para direcionar a secreção da proteína recombinante, o gene de resistência à zeocina $(S h$ Ble) para seleção em $E$. coli e $P$. pastoris e uma cauda de poli-histidina C-terminal, que permite a identificação e a purificação da proteína. A sequência de DNA foi sintetizada otimizando para códons usuais de $P$. pastoris, clonada entre EcoRI e XbaI, em frame com $\alpha$-factor na extremidade $5^{\prime}$ e $6 \times$ His e c-myc na extremidade 3' (Fig. 1).

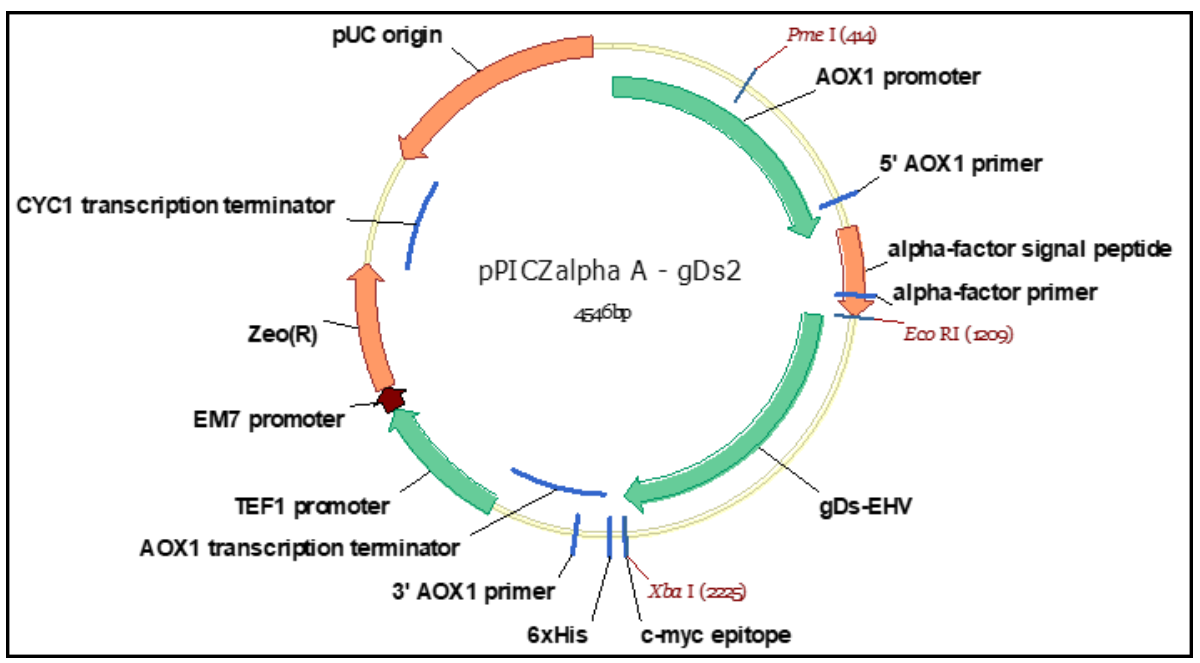

Figura 1. Representação gráfica do plasmídeo sintético pPICZ $\alpha$ A-gDEHV-1. Contém um fragmento de DNA de 1022 pb, que corresponde a uma fração da glicoproteína D do herpesvírus equídeo 1. 
O plasmídeo pPICZ $\alpha$ A-gDEHV-1 foi propagado em E. coli TOP10F (Invitrogen, SP, Brasil). Após a extração, linearização e purificação do DNA plasmidial, este foi utilizado para transformar $P$. pastoris estirpe $\mathrm{KM} 71 \mathrm{H}$ (Invitrogen, SP, Brasil), por eletroporação, em aparelho MicroPulser (Bio-Rad), conforme instruções do fabricante. Em placas de YPDS contendo zeocina (extrato de levedura 1\%, peptona $2 \%$, dextrose $2 \%$, sorbitol $18,22 \%$, ágar $2 \%$ e zeocina $100 \mu \mathrm{g} / \mathrm{mL}$ ), foram selecionados 63 clones recombinantes, numerados em ordem crescente e armazenados a $-20{ }^{\circ} \mathrm{C}$ em microtubos de $1,5 \mathrm{~mL}$ contendo $400 \mu \mathrm{L}$ de YPD e $100 \mu \mathrm{L}$ de glicerol $80 \%$, para posterior processamento, conforme descrito por Dummer et al. (2009).

Colônias isoladas dos clones $\mathrm{Mut}^{\mathrm{S}}$ foram inoculadas em frascos Erlenmeyer de $500 \mathrm{~mL}$ contendo $100 \mathrm{~mL}$ de meio BMGY (extrato de levedura $1 \%$, peptona $2 \%$, fosfato de potássio $100 \mathrm{mM}$, YNB - yeast nitrogen base - 1,34\%, biotina $4 \times 10^{-5} \%$, glicerol $\left.1 \%, \mathrm{pH} 6,0\right) \mathrm{e}$ incubadas durante a noite em agitador orbital a $200 \mathrm{rpm}, 28^{\circ} \mathrm{C}$, até atingir $\mathrm{OD}_{600} \mathrm{~nm}=4(20 \mathrm{~h}$ 24h). As culturas, após esse período, foram centrifugadas a $3.000 \times \mathrm{g}$, durante cinco minutos, à temperatura ambiente, e os sobrenadantes descartados. Os sedimentos das culturas $\mathrm{Mut}^{\mathrm{S}}$ foram suspendidos em $10 \mathrm{~mL}$ de meio BMMY (extrato de levedura $1 \%$, peptona $2 \%$, fosfato de potássio $100 \mathrm{mM}, \mathrm{YNB}$ - yeast nitrogen base $1,34 \%$, biotina $4 \times 10^{-5} \%$, metanol $0,5 \%, \mathrm{pH}$ 6,0 ), a uma $\mathrm{OD}_{600} \mathrm{~nm}=1$, em frascos Erlenmeyer aletados de $100 \mathrm{~mL}$, e incubados em agitador orbital a $200 \mathrm{rpm}, 28^{\circ} \mathrm{C}$, por 96 horas (período da indução). As culturas foram suplementadas com metanol a $1 \%(\mathrm{v} / \mathrm{v})$, a cada 12 horas. Após esse processo, as culturas foram centrifugadas a $3.000 \times \mathrm{g} \mathrm{a} 4{ }^{\circ} \mathrm{C}$, durante cinco minutos. Os sobrenadantes foram separados, tratados com 1 $\mathrm{mM}$ de PMSF (phenylmethanesulfonyl fluoride) e congelados a $-20^{\circ} \mathrm{C}$ (EasySelect..., 2010).

Os sobrenadantes do material expresso pelos clones $\mathrm{Mut}^{\mathrm{S}}$ foram filtrados $\left(\right.$ Millex $^{\mathrm{TM}} 0,22 \mu \mathrm{m}$ ) e purificados em coluna de cromatografia de afinidade de íons $\mathrm{Ni}^{2+}$ (Ni-NTA, Qiagem), no sistema de purificação de proteínas $\ddot{\mathrm{A} K T A}{ }^{\mathrm{TM}}$ (GE Healthcare, WI, EUA). Após monitoração do resultado da purificação em SDS-PAGE 12\%, as alíquotas com detecção positiva foram reunidas e a proteína foi quantificada pelo método da curva-padrão de albumina sérica bovina (BSA).

A detecção da proteína foi realizada por Western blot, conforme Sambrook e Russel (2001). Após eletroforese (Electrophoresis Power Supply, model LPS-300 V, Loccus biotecnologia, Brasil) em gel de poliacrilamida 12\% (SDS-PAGE), as amostras foram transferidas para membrana de nitrocelulose (Amershan ${ }^{\mathrm{TM}}$ Hybond $^{\mathrm{TM}}$ - ECL GE Healthcare). A membrana foi dividida em duas partes e submetida a bloqueio com leite em pó desnatado Molico ${ }^{\circledR}\left(\right.$ Nestle $\left.^{\circledR}\right)$ a $3 \%$ em PBS-T (tampão fosfato-salino com $0,05 \%$ de Tween 20), por 60 minutos, à temperatura ambiente, sob agitação suave.

Após três lavagens com PBS-T, uma parte foi incubada com MAb anti-histidina (BD Pharmingen $^{\mathrm{TM}} \quad 6 \times \mathrm{His}$ antibody - $\mathrm{BD}$, Biosciences), na diluição 1:5.000, e a outra parte com um pool de soros de três equinos positivos para EHV-1 (títulos 32, 64 e $\geq 256$ ) em partes iguais, na diluição 1:100, também em PBS-T, por 60 minutos, à temperatura ambiente, sob agitação suave. Após três lavagens com PBS-T, foram colocados os conjugados anti-mouse IgGperoxidase e anti-horse IgG-peroxidase (SigmaAldrich $^{\circledR}$ ), respectivamente, na diluição 1:5.000, em PBS-T, por 60 minutos, à temperatura ambiente, sob agitação suave. Posteriormente, as membranas foram lavadas cinco vezes com PBS$\mathrm{T}$ e receberam a solução de revelação $(9 \mathrm{~mL}$ TRIS $\mathrm{HCl} 50 \mathrm{mM}, 1 \mathrm{~mL}$ de sulfato de níquel 0,3\%, 0,006 g de DAB - 3,3'-diaminobenzidina tetra-hidrocloreto, $100 \mu \mathrm{L}$ de $\mathrm{H}_{2} \mathrm{O}_{2}$ ), durante 30 minutos, à temperatura ambiente, sob agitação suave. Após cinco lavagens com água destilada, as membranas foram deixadas para secar sobre papel-filtro para leitura posterior.

Algumas amostras da proteína sofreram digestão pela enzima Endo H (Endoglycosidase H, New England BioLabs, EUA), conforme instruções do fabricante (Usage..., 2016), para visualização no Western blot com MAb anti-histidina.

Duas vacinas com adjuvante hidróxido de alumínio $\quad\left(\right.$ Sigma-Aldrich $\left.^{\circledR}\right) \quad 10 \%$ foram formuladas: a primeira com $200 \mu \mathrm{g}$ da $\mathrm{rgDEHV}$ $1 / \mathrm{mL}$, e a segunda com PBS. Uma vacina comercial inativada, formulada para equídeos, contendo EHV-1 e EHV-4, também com adjuvante hidróxido de alumínio $10 \%$, foi 
adquirida em estabelecimento comercial. As vacinas foram utilizadas em camundongos BALB/c machos, com 28 dias de idade, agrupados aleatoriamente em três grupos de 10 animais cada, os quais receberam duas doses de vacina com intervalo de 21 dias (dias zero e 21), por via intramuscular (experimento aprovado pela Comissão de Ética em Experimentação Animal - Ceea - da Universidade Federal de Pelotas, sob o número Ceea 5727). Amostras de sangue foram coletadas, para obtenção de soro, nos dias zero, 21, 28, 35 e 47, coletadas das veias submandibulares.

Os soros dos camundongos foram testados por ELISA. Para isso, placas de poliestireno Costar $^{\text {TM }}$ high binding - 96-well) foram sensibilizadas por 18 horas, a $4{ }^{\circ} \mathrm{C}, 100 \mu \mathrm{L} /$ poço, com o antígeno rgDEHV-1, na concentração de 50 ng/poço, diluído em tampão carbonato bicarbonato $\mathrm{pH}$ 9,6. Após três lavagens com PBS-T, realizou-se bloqueio dos poços com 150 $\mu \mathrm{L}$ de leite em pó desnatado Molico ${ }^{\circledR}$ (Nestle ${ }^{\circledR}$ ) a $5 \%$, em PBS-T, por 60 minutos, a $37^{\circ} \mathrm{C}$. Passado esse tempo, as placas sofreram três lavagens com PBS-T, e os soros, diluídos em PBS-T na concentração de 1:100, foram colocados em duplicata na placa e incubados a $37^{\circ} \mathrm{C}$, por 60 minutos. Após a incubação, as placas foram lavadas três vezes com PBS-T e receberam 100 $\mu \mathrm{L}$ do conjugado anti-mouse IgG-peroxidase (Sigma-Aldrich ${ }^{\circledR}$ ), produzido em coelho, diluído a 1:8.000, em PBS-T.

Finalmente, as placas foram lavadas, por cinco vezes, com PBS-T, e incubadas com a solução de revelação $(0,004 \mathrm{~g}$ de o-Phenylenediamine dihydrochloride, Sigma-Aldrich ${ }^{\circledR}, 10 \mathrm{~mL}$ de tampão citrato/fosfato e $10 \mu \mathrm{L}$ de $\mathrm{H}_{2} \mathrm{O}_{2}$ ), $100 \mu \mathrm{L} /$ poço, à temperatura ambiente, ao abrigo da luz, por 15 minutos. A revelação foi interrompida com a aplicação de $100 \mu \mathrm{L} /$ poço de solução de ácido sulfúrico 3\%. A leitura de absorbância foi realizada em leitor de microplacas Reader (Termoplate), utilizando-se filtro de comprimento de onda de $490 \mathrm{~nm}$. As análises estatísticas foram feitas com o software Statistix 10. Foi realizada a análise de variância (ANOVA) com comparação entre médias não relacionadas pelo teste de Tukey.

\section{RESULTADOS}

Após 96h do início da fase de indução, o sobrenadante do cultivo de $P$. pastoris estirpe KM71H clone 30 foi filtrado e purificado. Em gel de SDS-PAGE $12 \%$, observou-se maior concentração de proteína nas frações 4 e 5 da purificação (Fig. 2). Após a purificação, a concentração da proteína foi estimada em 157 $\mathrm{mg} / \mathrm{L}$, pelo método da curva-padrão de albumina sérica bovina.

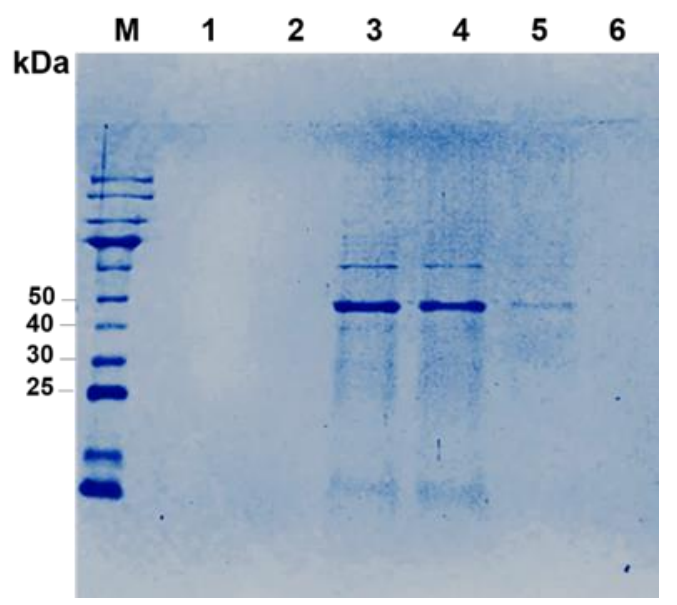

Figura 2. Eletroforese em gel de SDS-PAGE $12 \%$. Frações 4, 5 e 6 da purificação da glicoproteína D recombinante do herpesvírus equídeo 1 (peso molecular $\sim 41 \mathrm{kDa}$ ), a partir do sobrenadante do cultivo do clone 30, expressa em Pichia pastoris. $\mathrm{M}=$ marcador, $1=$ fração 2 da purificação, 2= fração 3 da purificação, $3=$ fração 4 da purificação, $4=$ fração 5 da purificação, $5=$ fração 6 da purificação, $6=$ fração 7 da purificação.

Foi possível observar em SDS-PAGE 12\%, por meio da análise das amostras de sobrenadantes dos cultivos, maior concentração da proteína $72 \mathrm{~h}$ após o início da fase de indução (dados não apresentados). Também foi possível observar, analisando as frações de eluição da purificação, um padrão entre $40 \mathrm{kDa}$ e $50 \mathrm{kDa}$, correspondendo a gD truncada do EHV-1 ( 41 $\mathrm{kDa})$, entretanto, no Western blot, o produto de alguns clones não foi identificado pelo $\mathrm{MAb}$ anti-histidina. Realizou-se, então, o tratamento com a enzima Endo $\mathrm{H}$, que permitiu a identificação de uma banda proteica entre 25 $\mathrm{kDa}$ e $37 \mathrm{kDa}$. O resultado pode ser observado nas colunas 3 e 5 da Fig. 3. 
A deglicosilação promovida pela enzima Endo $\mathrm{H}$ possibilitou a identificação da rgDEHV-1 nos clones que anteriormente não tiveram a proteína identificada pelo MAb anti-histidina. Para confirmar a antigenicidade da glicoproteína D recombinante, foi realizado um Western blot utilizando um pool de soros de equinos, naturalmente infectados, contendo anticorpos policlonais anti-EHV-1 (Fig. 4).

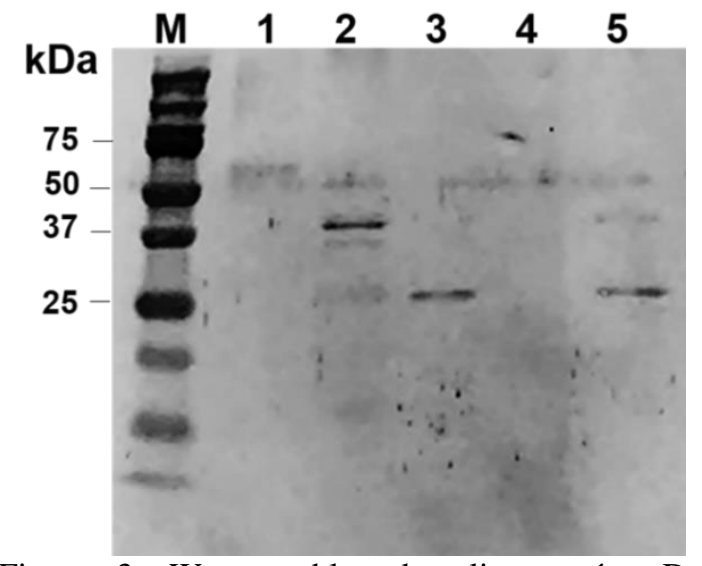

Figura 3. Western blot da glicoproteína D recombinante do herpesvírus equídeo 1 ( 41 kDa), expressa em Pichia pastoris, marcada pelo anticorpo monoclonal anti-histidina. Não tratados pela enzima Endo $\mathrm{H}$ (1, 2 e 4); tratados pela enzima Endo H (3 e 5). $\mathrm{M}=$ marcador, 1= sobrenadante de Pichia pastoris KM71H não transformada, $2=$ produto da purificação do sobrenadante de três clones, $3=$ produto da purificação do sobrenadante de três clones, 4= produto da purificação do sobrenadante do clone $30,5=$ produto da purificação do sobrenadante do clone 30 .

Os anticorpos presentes nos soros dos equinos, infectados naturalmente, reconheceram epítopos na rgDEHV-1 expressa em P. pastoris (Fig. 4, coluna 2, entre $50 \mathrm{kDa}$ e $37 \mathrm{kDa}$ ), assim como identificaram, com menos intensidade, outros antígenos produzidos pela levedura não transformada (Fig. 4, coluna 1, entre $75 \mathrm{kDa}$ e 50 $\mathrm{kDa}$ ), o que demonstra a existência de anticorpos contra $P$. pastoris nesses equinos.

A avaliação da antigenicidade e da imunogenicidade da rgDEHV-1 foi realizada por ELISA indireto, com a utilização dos soros dos camundongos vacinados nos dias zero e 21 do experimento, e coletados nos dias zero, 21, 28, 35 e 47. Foram utilizadas as seguintes vacinas contendo hidróxido de alumínio a $10 \%$ como adjuvante: controle (PBS 1×), comercial (EHV1/EHV-4) e experimental (rgDEHV-1) (Fig. 5). Os resultados, expressos na Fig. 5, mostraram que os anticorpos induzidos pela vacina comercial e pela vacina de proteína recombinante reconheceram a rgDEHV-1 expressa em $P$. pastoris.

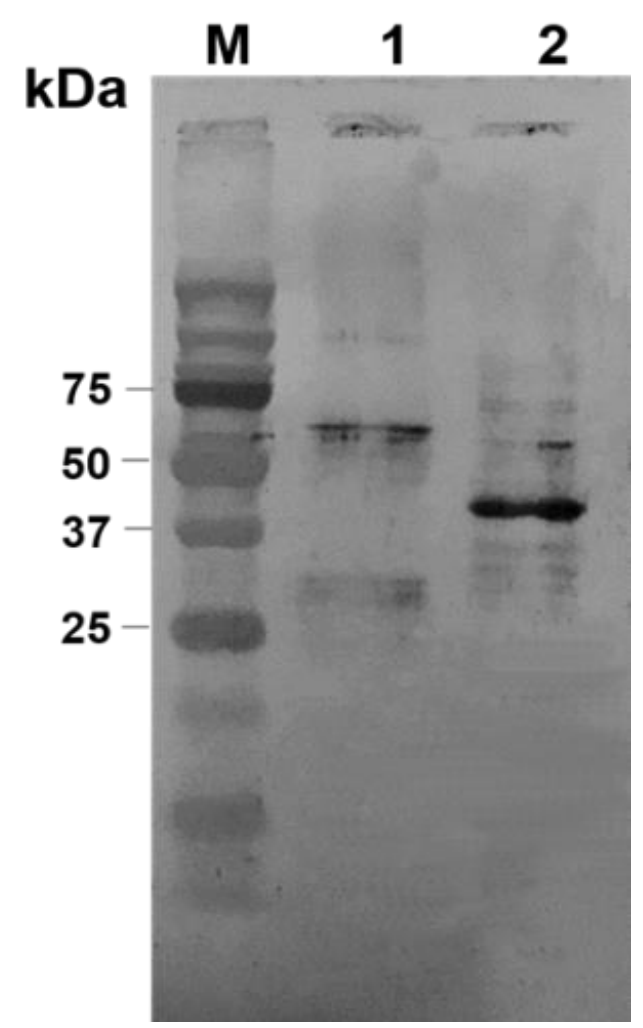

Figura 4. Western blot da glicoproteína D recombinante do herpesvírus equídeo 1 , expressa em Pichia pastoris, marcada por anticorpos policlonais anti-EHV-1, peso molecular $\sim 41 \mathrm{kDa}$ (2). $\mathrm{M}=$ marcador, $1=$ sobrenadante de Pichia pastoris $\mathrm{KM} 71 \mathrm{H}$ não transformada, $2=$ produto da purificação do sobrenadante de dois clones.

Após 21 dias da primeira vacinação, em nenhum dos grupos, os aumentos dos níveis de anticorpos anti-rgDEHV-1 foram significativos em relação ao grupo controle. No dia 28, sete dias após a segunda vacinação, somente o grupo gDEHV-1 mostrou título superior ao grupo controle. Nos dias 35 e 47, os dois grupos foram estatisticamente superiores ao grupo controle. No dia 47, 26 dias após a segunda dose de vacina, o grupo gDEHV-1 mostrou valores de absorbância 1,7 vez maior que o grupo vacina comercial e 3,7 vezes maiores que o grupo controle. 


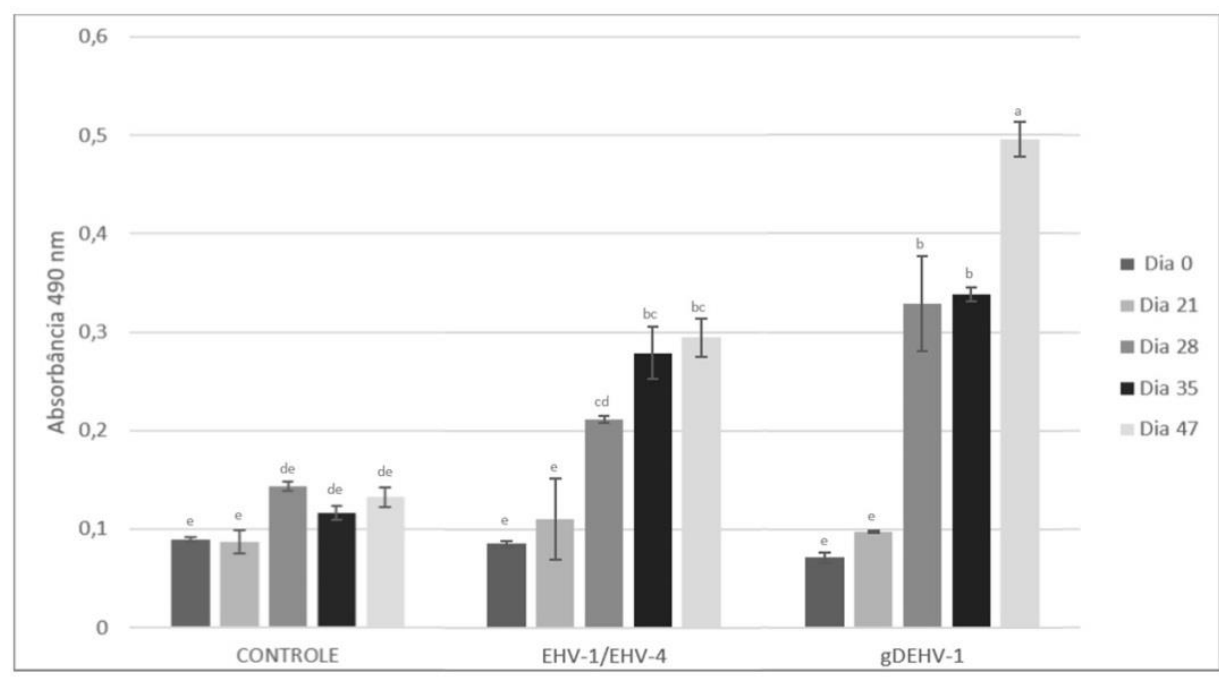

Figura 5. Níveis de anticorpos específicos contra a glicoproteína D recombinante do herpesvírus equídeo 1, expressa em Pichia pastoris, detectados por ELISA indireto. Os dados representam as médias em valores de ELISA de IgG total de camundongos BALB/c vacinados nos dias zero e 21, nos diferentes grupos vacinais, em função do tempo. Amostras (pool, $\mathrm{n}=10$ ) usadas na diluição 1:100, em duplicata, títulos expressos na absorbância de $490 \mathrm{~nm}$. Letras diferentes indicam diferença estatística pelo teste e Tukey $(\mathrm{P}<0,05)$.

\section{DISCUSSÃO}

Depois da purificação, obteve-se $\sim 157 \mathrm{mg} / \mathrm{L}$ da gDEHV-1 recombinante, resultado, no mínimo, $57 \%$ superior ao obtido por Ruitenberg et al. (2001), que, ao expressarem uma forma truncada da rgDEHV-1 em $P$. pastoris, também utilizando a estirpe $\mathrm{KM} 71 \mathrm{H}$, obtiveram de $50 \mathrm{mg} / \mathrm{L}$ a 100 $\mathrm{mg} / \mathrm{L}$. A concentração máxima da proteína foi obtida $72 \mathrm{~h}$ após o início da fase de indução, resultado divergente do encontrado por Ruitemberg et al. (2001), que detectaram máxima concentração após $48 \mathrm{~h}$ da indução. A linhagem de $P$. pastoris escolhida para a recombinação/incorporação do plasmídeo sintético, KM71H, possui fenótipo Mut ${ }^{\mathrm{S}}$, ou seja, o gene AOX1 foi deletado, ficando a metabolização do metanol sob condução do gene AOX2, responsável por apenas $15 \%$ da atividade AOX total na célula. Entretanto, conforme Krainer et al. (2012), vários estudos mostraram a superioridade das estirpes $\mathrm{Mut}^{\mathrm{S}}$ sobre as $\mathrm{Mut}^{+}$ em relação à produção de proteínas recombinantes.

No Western blot, o MAb anti-histidina identificou uma banda proteica de $\sim 41 \mathrm{k}$ Da e, após o tratamento com a enzima Endo H, uma banda entre $25 \mathrm{kDa}$ e $37 \mathrm{kDa}$, evidenciando uma glicosilação entre $4 \mathrm{kDa}$ e $16 \mathrm{kDa}$. Isso demonstra que a $\mathrm{N}$-glicosilação promovida pela $P$. pastoris, em alguns clones, possivelmente impediu a identificação pelo MAb anti-histidina. Nesses casos, a glicosilação pós-traducional possivelmente encobriu o epítopo $6 \times$ His-tag, impossibilitando a ligação do anticorpo antihistidina. Resultados semelhantes foram obtidos por Ruitemberg et al. (2001), que encontraram produtos específicos da rgDEHV-1 entre 200 $\mathrm{kDa}$ e $40 \mathrm{kDa}$, e, após tratamento com as enzimas PNGase $\mathrm{F}$ e Endo $\mathrm{H}$, quatro bandas de $48 \mathrm{kDa}, 45 \mathrm{kDa}, 34 \mathrm{kDa}$ e $>15 \mathrm{kDa}$ foram evidenciadas, demonstrando que a proteína sofreu uma hiperglicosilação, o que também impedia a identificação pelo MAb anti-histidina. Scorer et al. (1993), ao produzirem a glicoproteína gp120, do envelope do vírus da imunodeficiência humana tipo 1 (HIV-1), em $P$. pastoris, verificaram que uma elevada proporção do produto secretado era hiperglicosilado. Conforme Audonnet et al. (1990), a gD do EHV1 possui quatro sítios potenciais para $\mathrm{N}$ glicosilação.

Os resultados do ELISA mostraram que a proteína recombinante conservou epítopos que permitiram sua identificação por anticorpos policlonais anti-EHV-1 e anti-gDEHV-1 
produzidos por vacinação. Camundongos vacinados com a proteína recombinante mostraram valores de absorbância estatisticamente superiores ao grupo controle nos dias sete, 14 e 26 após a segunda inoculação. Ruitenberg et al. (2001) obtiveram resultados muito semelhantes ao realizarem duas inoculações, com quatro semanas de intervalo, em camundongos BALB/c fêmeas, com a gDEHV-1 expressa em $P$. pastoris. Weerasinghe et al. (2006) também alcançaram resultados semelhantes ao fazerem duas inoculações, com 30 dias de intervalo, em camundongos BALB/c, com a gDEHV-1 expressa em E. coli e baculovírus.

\section{CONCLUSÃO}

A proteína gDEHV-1 recombinante, expressa em Pichia pastoris, foi caracterizada antigenicamente e imunogenicamente por Western blot e por ELISA indireto em modelo murino. Os resultados encontrados permitem concluir que a proteína conservou epítopos que possibilitaram sua identificação por anticorpos presentes nos soros de equinos naturalmente infectados pelo EHV-1 e por anticorpos específicos anti-EHV-1 induzidos por vacina comercial, formulada com vírus íntegros inativados, e por vacina experimental, formulada com a proteína recombinante.

\section{REFERÊNCIAS}

AHMAD, M.; HIRZ, M.; PICHLER, H.; SCHWAB, H. Protein expression in Pichia pastoris: recent achievements and perspectives for heterologous protein production. Appl. Microbiol. Biotechnol., v.98, p.5301-5317, 2014.

AUDONNET, J.C.; WINSLOW, J.; ALLEN, G.; PAOLETTI, E. Equine herpesvirus type 1 unique short fragment encodes glycoproteins with homology to herpes simplex vírus type $1 \mathrm{gD}$, gI and gE. J. Gen. Virol., v.71, p.2969-2978, 1990.

CREGG, J.M.; CEREGHINO, J.L.; SHI, J.; HIGGINS, D.R. Recombinant protein expression. in Pichia pastoris. Mol. Biotechnol., v.1, p.23-52, 2000.
DUMMER, L.A.; CONCEIÇÃO, F.R.; NIZOLI, L.Q. et al. Cloning and expression of a truncated form of envelope 2 glycoprotein D of Bovine herpesvirus type 5 in methylotrophic yeast Pichia pastoris. J. Virol. Methods, v.161, p.8490, 2009.

EASYSELECT ${ }^{\mathrm{TM}}$ pichia expression kit manual for expression of recombinant proteins using pPICZ and pPICZ $\alpha$ in Pichia Pastoris. [s.1.]: Invitrogen, 2010. Cat. n. K1740-01, 86p. Disponível em: <http://tools.thermofisher.com/content/sfs/manua ls/easyselect_man.pdf $>$. Acessado em: $10 \mathrm{dez}$. 2018.

FLOWERS, C.C.; O'CALLAGHAN, D.J. Equine herpesvirus 1 glycoprotein D: mapping of the transcript and a neutralization epitope. $J$. Virol., v.66, p.6451-6460, 1992.

FOOTE, C.E.; LOVE, D.N.; GILKERSON, J.R.; ROTA, J.; TREVOR-JONES, P. et al. Serum antibody responses to equine herpesvirus 1 glycoprotein D in horses, pregnant mares and young foals. Vet. Immunol. Immunopathol., v.105, p.47-57, 2005.

FUENTEALBA, N.; SGUAZZA, G.; SCROCHI, M.; BRAVI, M. et al. Production of equine herpesvirus 1 recombinant glycoprotein $\mathrm{D}$ and development of an agar gel immunodiffusion test for serological diagnosis. J. Virol. Methods, v.202, p.15-18, 2014.

HARLESS, W.; PUSTERLA, N. Equine herpesvirus 1 and 4 respiratory disease in the horse. J. Clin. Techn. Equine Pract., v.5, p.197202, 2006.

KRAINER, F.W.; DIETZSCH, C.; HAJEK, T.; HERWIG, C. et al. Recombinant protein expression in Pichia pastoris strains with an engineered methanol utilization pathway. Microbial. Cell. Factories, v.11, p.1-14, 2012.

LOVE, D.N.; BELL, C.W.; PYE, D.; EDWARDS, S. et al. Expression of Equine Herpesvirus 1 Glycoprotein $\mathrm{D}$ by Using a Recombinant Baculovirus. J. Virol., v.67, p.6820-6823, 1993.

LOVE, D.N.; BELL, C.W.; WHALLEY, J.M. Characterization of the glycoprotein $\mathrm{D}$ gene products of equine herpesvirus 1 using a prokaryotic cell expression vector. Vet. Microbiol., v.30, p.387-394, 1992. 
MAXWELL, L.K. Antiherpetic drugs in equine medicine. Vet. Clin. N. Am. Equine Pract., v.33, p.99-125, 2017.

PATEL, J.R.; HELDENS, J. Equine herpesviruses 1 (EHV-1) and 4 (EHV-4) epidemiology, disease and immunoprophylaxis: a brief review. Vet. J., v.170, p.14-23, 2005.

RUITENBERG, K.M.; GILKERSON, J.R.; WELLINGTON, J.E. et al. Equine herpesvirus 1 glycoprotein D expressed in Pichia pastoris is hyperglycosilated and elicits a protective immune response in the mouse model of EHV-1 disease. Virus Res., v.79, p.125-135, 2001.

SÁENZ， J.R.; URCUQUI-INCHIMA， S. Replicación del herpesvirus equino y su asociación con la patogénesis molecular. Acta Biol. Colomb., v.11, p.1-18, 2006.

SAMBROOK, J.; RUSSEL, D.W. Molecular cloning: a laboratory manual. 3.ed. New York: Cold Spring Harbor Lab. Press, 2001.

SCORER, C.A.; BUCKHOLZ, R.G.; CLARE, J.J.; ROMANES, M.A. The intracellular production and secretion of HIV-1 envelope protein in the methylotrophic yeast Pichia pastoris. Gene, v.136, p.111-119, 1993.

STOKES, A.; CAMERON, R.S.; MARSHALL, R.N.; KILLINGTON, R.A. High level expression of equine herpesvirus 1 glycoproteins $\mathrm{D}$ and $\mathrm{H}$ and their role in protection against virus challenge in the $\mathrm{C} 3 \mathrm{H}\left(\mathrm{H}-2 \mathrm{~K}^{\mathrm{k}}\right)$ murine model. Virus Res., v.50, p.159-173, 1997.
Usage Information - SDS-PAGE analysis of protein deglycosylation using Endo H. Promega 2016. Disponível em: <www.promega.com.br//media/files/resources/protocols/productinformation-sheets/n/endo-h-protocol.pdf?la=ptbr>. Acessado em: 10 dez. 2018.

WEERASINGHE, C.U.; LEARMONTH, G.S.; GILKERSON, J.R. et al. Equine herpesvirus 1 glycoprotein D expressed in $E$. coli provides partial protection against equine herpesvirus infection in mice and elicits virus-neutralizing antibodies in the horse. Vet. Immunol. Immunopathol., v.111, p.59-66, 2006.

WHITTAKER, G.R.; TAYLOR, L.A.; ELTON, D.M.; GILES, L.E. et al. Glycoprotein 60 of equine herpesvirus type 1 is a homologue of herpes simplex virus glycoprotein $\mathrm{D}$ and plays a major role in penetration of cells. J. General Virol., v.73, p.801-809, 1992.

ZHANG, Y.; SMITH, P.M.; TARBET, E.T.; OSTERRIEDER, N. et al. Protective immunity against equine herpesvirus type-1 (EHV-1) infection in mice induced by recombinant EHV-1 gD. Virus Res., v.56, p.11-24, 1998. 